\title{
An Investigation of the Effect of Graphite Degradation on the Irreversible Capacity in Lithium-ion Cells
}

\author{
Laurence J. Hardwick $^{*}$, Marek Marcinek ${ }^{\mathrm{a}^{*}}$, Leanne Beer, John B. Kerr*, \\ Robert Kostecki, ${ }^{\text {b, }}$ \\ Environmental Energy Technologies Division, \\ Lawrence Berkeley National Laboratory, \\ Berkeley, CA 94720, USA
}

*Electrochemical Society Active Member

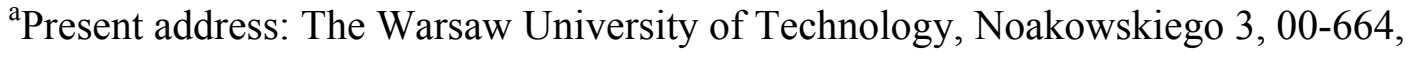
Warsaw, Poland

${ }^{\text {b}}$ Corresponding author: r_kostecki@lbl.gov, tel: (1) 510486 6002, fax: (1) 5104867303 


\begin{abstract}
The effect of surface structural damage on graphitic anodes, commonly observed in tested Li-ion cells, was investigated. Similar surface structural disorder was artificially induced in Mag-10 synthetic graphite anodes using argon-ion sputtering. Raman microscopy, scanning electron microscopy (SEM) and Brunauer Emmett Teller (BET) measurements confirmed that Ar-ion sputtered Mag-10 electrodes display similar degree of surface degradation as the anodes from tested Li-ion cells. Artificially modified Mag10 anodes showed double the irreversible charge capacity during the first formation cycle, compared to fresh un-altered anodes. Impedance spectroscopy and Fourier transform infrared (FTIR) spectroscopy on surface modified graphite anodes indicated the formation of a thicker and slightly more resistive SEI layer. Gas chromatography/mass spectroscopy (GC/MS) analysis of solvent extracts from the electrodes detected the presence of new compounds with $\mathrm{M}_{\mathrm{w}}$ on the order of $1600 \mathrm{~g} \mathrm{~mol}^{-1}$ for the surface modified electrode with no evidence of elevated $M_{w}$ species for the unmodified electrode. The structural disorder induced in the graphite during long-term cycling maybe responsible for the slow and continuous SEI layer reformation, and consequently, the loss of reversible capacity due to the shift of lithium inventory in cycled Li-ion cells.
\end{abstract}




\section{Introduction}

Understanding the mechanism of ageing processes and degradation modes of Li-ion systems still remains an important objective for battery research. ${ }^{1}$ This is most notably for Li-ion batteries for transportation applications, where $10-15$ years battery lifetime is required. ${ }^{2}$ It has been previously shown that the graphite anodes suffer severe surface structural damage upon prolonged cycling in rechargeable lithium-ion batteries. ${ }^{3,4,5}$ This is evidenced in the Raman spectra of graphite anodes from tested Li-ion cells by the increased prominence of the D-band $\left(\sim 1330 \mathrm{~cm}^{-1}\right)$ with respect to the G-band (1580 $\left.\mathrm{cm}^{-1}\right)$. This effect has been reported for Mag- $10^{3}$ and KS- $15^{4}$ graphite anodes and seems to occur generally in all graphitic carbons.

The space between the graphene layers in graphite increases from 3.35 to $3.7 \AA$ upon lithium intercalation and is followed by a subsequent rearrangement from either $\mathrm{ABAB}$ or $\mathrm{ABCABC}$-type layers in pure graphite to AAAA-type layers, in the case of $\mathrm{LiC}_{6}{ }^{6,7,8}$ Though this is not an extreme structural rearrangement in itself, it leads to a build-up of internal mechanical stress within the graphene crystal lattice and results in local structural damage of graphene sheets within graphite crystallites. This deleterious effect is intensified at high charging rates and elevated temperatures, 3,9 which both may cause greater disparity of lithium concentration within a graphite particle. Variation of lithium concentration within and between graphite particles was observed in anodes, even at very low charge rates of $C / 37 .^{10}$ 
The surface structural damage of the graphitic anode, which is commonly observed in anodes from tested Li-ion cells, does not change the reversible charge capacity of the graphite. However, it may modify the physical and chemical properties of the SEI layer, and affect significantly lithium-ion cell long-term behaviour. In this study we investigate the effect of the surface structural damage in graphite on the electrochemical performance of the graphite-based anodes. Surface structural disorder in model graphite Mag-10 anodes was artificially recreated using argon-ion sputtering. A diagnostic evaluation of these surface-modified model anodes in the Li-ion system is carried out and possible implications for Li-ion cell degradation mechanism are discussed.

\section{Experimental}

Thin-film Mag-10 composite anodes (graphite 92\%, polyvinyldenedifluoride (PVdF) 8\%, (loading $10 \mathrm{mg} \mathrm{cm}^{-2}$ )) were produced from N-methyl pyridine (NMP) slurry coated onto a $\mathrm{Cu}$ foil. Argon-ion sputtering was used to artificially induce disorder on the surface graphite particles of the electrode. The graphite electrode was used as a target in the sputtering chamber (Cool Sputter Coater, BAL-TEC); the reactor was flushed several times with Ar and evacuated to $3 * 10^{-3}$ Torr. Sputtering of the anode was carried out at various time intervals at a constant current density of $2 \mathrm{~mA} \mathrm{~cm}$.

The surface structure of un-altered and sputtered graphite in composite Mag-10 anodes was analyzed by Raman microscopy (Labram, ISA Groupe Horiba) with laser excitation wavelength $632.8 \mathrm{~nm}$ at $1 \mathrm{~mW}$ power at the sample. Raman maps consisting of 5400 individual points over an area of $48 \times 74 \mu \mathrm{m}$ were collected in autofocus mode with a 
spatial resolution of ca. $0.7 \mu \mathrm{m}$. The surface morphology was characterised by scanning electron microscopy (SEM, S-4300 SE/N, Hitachi).

The surface area of un-altered and sputtered Mag-10 graphite samples was determined by Brunauer Emmett Teller (BET) nitrogen gas adsorption measurements (2375 Gemini, Micrometrics) at $77 \mathrm{~K}$. The samples consisted of $700 \mathrm{mg}$ graphite disks of $2 \mathrm{~mm}$ thickness and ca. $50 \mathrm{~mm}$ diameter, which were pressed at $103 \mathrm{MPa}$ using a stainless steel die. The graphite discs were sputtered for either 120 or $1800 \mathrm{~s}$, and then broken up into a powder and dried at $300^{\circ} \mathrm{C}$ under a flow of argon for 3 hours prior to the BET measurements.

All electrochemical measurements were carried out at room temperature $\left(23{ }^{\circ} \mathrm{C}\right)$ in a glove box (Nexus II, Vacuum Atmospheres Company, He atmosphere, water and oxygen content below $1 \mathrm{ppm})$. Prior to electrochemical tests the electrodes were dried at $120^{\circ} \mathrm{C}$ under vacuum for 3 days and then transferred to the glove box without exposing them to the air. The Mag-10 anodes were galvanostatically cycled in a sealed beaker cell equipped with lithium-foil counter and reference electrodes and filled with 1.0 $\mathrm{M} \mathrm{LiPF}_{6}$, ethylene carbonate (EC): dimethyl carbonate (DMC) 1:1 w/w electrolyte (EM Science), using a Computer Controlled Cell Capture (CCCC, Astrol Electronics AG). The galvanostatic charge/discharge current was ca. $0.15 \mathrm{~mA} \mathrm{~cm}^{-2}$, which corresponds to a rate of $C / 25$ ( $C$ denotes the theoretical charge capacity of the carbon electrode $\left(372 \mathrm{Ah} \mathrm{kg}^{-1}\right)$ and $C / 25$ corresponds to a current allowing a full discharge in 25 hours). 
Mag-10 graphite electrodes were cycled at $C / 25$ from open circuit potential ca. $3.0 \mathrm{~V}$ vs. $\mathrm{Li} / \mathrm{Li}^{+}$(first scan) to $0.01 \mathrm{~V}$ and then between $1.0 \mathrm{~V}$ and $0.01 \mathrm{~V}$ for a total of three cycles. At the end of the third charge scan of the Mag-10 anodes, electrochemical impedance spectra were measured over a frequency range of $10 \mathrm{mHz}$ to $50 \mathrm{kHz}$ at $0.05 \mathrm{~V}$ (Femtostat, Gamry Instruments). After the third discharge scan the anodes were removed from the beaker cell, washed with dry DMC to remove any remaining residual $\mathrm{EC}$ and $\mathrm{LiPF}_{6}$, and dried in the glove box. The electrodes were placed in an air-tight spectroscopic cell equipped with a $\mathrm{KBr}$ optical window. The SEI layer formed on the electrochemically cycled Mag-10 anodes was examined with a Fourier transform infrared (FTIR) microscope (Continu $\mu \mathrm{m}$ Nexus 870, Nicolet).

GC measurements were performed on an Agilent 5890 Series II plus gas chromatograph with a SPB5 column (Supelcowax $30 \mathrm{~m}, 0.32 \mathrm{~mm}$ ID, film thickness $0.25 \mu \mathrm{m}$ ) and carrier gas of helium ( $3 \mathrm{ml} / \mathrm{min})$ with on column fused silica injection equipped with a flame ionization detector and a temperature program of $2.5 \mathrm{~min}$ at $-15^{\circ} \mathrm{C}, 10{ }^{\circ} \mathrm{C} / \mathrm{min}$ to $230{ }^{\circ} \mathrm{C}$ and $15 \mathrm{~min}$ at $230{ }^{\circ} \mathrm{C}$. GC-MS measurements were performed on an Agilent 6890 Series GC System/5973 Network MSD with a SPB5 column (Supelcowax 30 m, $0.32 \mathrm{~mm}$ ID, film thickness $0.25 \mu \mathrm{m})$ and carrier gas of helium $(2.3 \mathrm{ml} / \mathrm{min})$ and a temperature program of $5 \mathrm{~min}$ at $15{ }^{\circ} \mathrm{C}, 10{ }^{\circ} \mathrm{C} / \mathrm{min}$ to $230{ }^{\circ} \mathrm{C}$ and $15 \mathrm{~min}$ at $230{ }^{\circ} \mathrm{C}$. The MSD was operated in electron ionization (EI) mode.

Materials of higher molecular weight were characterised by gel permeation chromatography (GPC) using an Agilent 1100 Series HPLC equipped with a refractive 
index detector. A PLgel $5 \mu \mathrm{m}$ miniMIX-C $250 \times 4.6 \mathrm{~mm}$ column was employed with DMF eluent and calibrated by using polyethylene oxide (PEO) standard samples in DMF with molecular weights ranging from 400 to $997000 \mathrm{~g} \mathrm{~mol}^{-1}$.

\section{Results}

The structure and morphology of the sputtered Mag-10 anodes were studied and compared with the fresh un-altered Mag-10 electrode. A representative SEM image of an unaltered Mag-10 anode (Figure 1a) shows graphite particles that consist of flat and smooth graphene sheets with clearly pronounced linear steps and edges. Conversely, the SEM micrograph of the Mag-10 electrode which was sputtered for $120 \mathrm{~s}$ (Figure 1b) shows a much higher surface density of small graphene zones with irregularly shaped edges. The Ar-ion bombardment knocked out carbon atoms from the hexagonal lattice of the surface graphene sheets and created local shallow structural disorder. Interestingly, the carbon etching appears highly non-uniform and tends to break large surface graphene sheets into smaller domains. Nevertheless Ar-ion bombardment, for this short time scale and low current density, did not cause graphite particle breakdown. No evidence of deepetching or exfoliation of the graphene layers was found, as it is often observed during exposure of graphitic carbons to short high-intensity pulse ion beams. ${ }^{11}$

Brunauer Emmett Teller (BET) comparative measurements of the un-altered and sputtered Mag-10 graphite powders reveal that Ar-ion bombardment induces no significant variation in surface area, even after a prolonged sputtering for $1800 \mathrm{~s}$ (Table 1). The SEM pictures of the sputtered Mag-10 electrodes indicate higher content of 
surface edge sites. No significant surface area increase, as determined by the BET measurement, confirms that no exfoliation or graphite particle breakdown occurred during sputtering. ${ }^{12}$

The Raman spectra of un-altered and sputtered anodes are shown in Figure 2a. The spectra exhibit two intense peaks assigned to the G- and D-band at 1580 and $1330 \mathrm{~cm}^{-1}$ that correspond respectively to the $E_{2 \mathrm{~g} 2}$ and $A_{1 \mathrm{~g}}$ carbon vibrational modes. ${ }^{13}$ The G-band is the only apparent Raman active mode of the infinite lattice (there is another band, $E_{2 \mathrm{~g} 1}$ at $42 \mathrm{~cm}^{-1}$, however its proximity to the Rayleigh line makes it difficult to observe). The G-band results from the relative motion of $\mathrm{sp}^{2}$ carbon atoms in rings, as well as in chains. ${ }^{14}$ The D-band is associated with the breakage of symmetry occurring at point defects and at the edges of the graphene sheets, ${ }^{15}$ and is attributed to the breathing motion of $\mathrm{sp}^{2}$ carbon six member rings. A small shoulder on the G-band at $1610 \mathrm{~cm}^{-1}$ is known as the D'-band and is also attributed to discontinuity and disorder within graphene plane. The exact origin of this band is still under discussion but it is believed to arise from a relaxation of the $\mathrm{q}=0$ selection rule, which allows higher frequency phonons to become Raman active, as phonons disperse upwards away from $\Gamma$ in the first Brillouin zone of graphite. $^{14,16,17}$

The D-band to G-band integrated area ratio $\left(I_{\mathrm{D}} / I_{\mathrm{G}}\right)$ is often used as a parameter for evaluating carbon structural properties. ${ }^{3,4}$ The increased intensity of the D-band relative to the G-band is typically associated with (a) higher content of disordered carbon and/or (b) decrease of the graphite crystallite size in the a direction $\left(L_{\mathrm{a}}\right){ }^{13}$ 
The Raman spectra of the un-altered and sputtered Mag-10 electrodes (Figure 2a) clearly show that the intensity of the D and D' "disorder" bands at 1330 and $1610 \mathrm{~cm}^{-1}$ enlarges significantly with respect to the G-band $\left(1580 \mathrm{~cm}^{-1}\right)$ with the sputtering time. Rapid increase of the $I_{\mathrm{D}} / I_{\mathrm{G}}$ ratio from 0.23 for the un-altered electrode to 1.28 after sputtering for $30 \mathrm{~s}$ followed by a moderate increase to 1.4 for Mag-10 anodes sputtered for $120 \mathrm{~s}$ (Figure 2b) indicates that most of surface disorder is induced into graphite during the first 30 seconds and then layers of graphite are slowly etched away.

Representative Raman maps (Figure 3) of un-altered (a) and 120s sputtered (b) Mag-10 graphitic anodes display the surface distribution of the $I_{\mathrm{D}} / I_{\mathrm{G}}$ ratio. The $I_{\mathrm{D}} / I_{\mathrm{G}}$ ratios were derived from individual deconvoluted Raman spectra recorded at $0.7 \mu \mathrm{m}$ spatial resolution. Light areas on the map correspond to highly graphitic carbon with low $I_{\mathrm{D}} / I_{\mathrm{G}}$ ratios, whereas dark areas represent disordered graphite with elevated $I_{\mathrm{D}} / I_{\mathrm{G}}$ ratios. The map of the sputtered electrode displays a wide distribution of the $I_{\mathrm{D}} / I_{\mathrm{G}}$ ratio $<2$ with large contribution from disordered graphite (dark areas) whereas the map of the unaltered electrode displays the majority of the $I_{\mathrm{D}} / I_{\mathrm{G}}$ ratio below 0.4 . Variation of the surface structural damage in the sputtered graphitic anodes originates most likely from a non-uniform sputtering current distribution during Ar-ion bombardment. Anisotropic electronic conductivity of graphite and random distribution of contact resistances within the composite anode contributed to this effect. 
Raman measurements reveal a striking similarity of the surface structure disorder of Arion sputtered Mag-10 electrodes and Mag-10 anodes from tested Li-ion cells. ${ }^{3}$ The average surface disorder of the Mag-10 electrode sputtered for $120 \mathrm{~s}$ corresponds exactly to the structural damage observed in Mag-10 anodes removed from tested Li-ion cells, which suffered severe power and capacity loss. ${ }^{18}$ Interestingly, Raman maps of the $I_{\mathrm{D}} / I_{\mathrm{G}}$ ratio of the Mag-10 graphite anodes from tested Li-ion cells show a non-uniform surface structural degradation pattern, which is nearly identical to the Ar-ion sputtered electrodes. Thus, we postulate that using argon-ion sputtering we were able to re-create the type and degree of surface structural disorder observed in graphitic anodes from tested Li-ion cells.

The first galvanostatic charge and discharge scans of the un-altered and sputtered Mag-10 anodes are shown in Figure 4. Lithium intercalation into graphite occurs at potentials below $0.2 \mathrm{~V}$ vs. $\mathrm{Li} / \mathrm{Li}^{+}$. However a significant amount of charge of ca. 35 and $80 \mathrm{Ah} \mathrm{kg}^{-1}$ has been consumed above $0.2 \mathrm{~V}$ for un-altered and sputtered Mag-10 anodes, respectively. This irreversible charge originates from the reduction of the electrolyte and formation of the solid electrolyte interphase (SEI), which occurs at potentials $<0.85$ V. ${ }^{19,20}$ The SEI inhibits further electrolyte decomposition but allows the transfer of lithium-ions from the electrolyte into the graphite. ${ }^{12,21}$ The small amount of charge consumed at potentials above $1.0 \mathrm{~V}$ is mainly associated with the reduction of surface groups, as well as lithium salt decomposition. ${ }^{22}$ This effect is more pronounced for the sputtered electrode and is likely associated with the higher surface density of oxygen-rich 
surface groups which formed upon exposure of the freshly sputtered Mag-10 anode to the air.

The first charge for un-altered and sputtered Mag-10 anodes consumed ca. 400 and 530 $\mathrm{Ah} \mathrm{kg}^{-1}$, correspondingly. The sputtering process did not affect the reversible charge capacity ( $\mathrm{q}^{\prime}$ rev $)$ of the electrode $\left(\sim 350 \mathrm{Ah} \mathrm{kg}^{-1}\right)$, which is close to the theoretical value for graphite of $372 \mathrm{Ah} \mathrm{kg}^{-1}$. However, the irreversible capacity loss qirr increased from $18 \pm 1$ for the un-altered electrode to $34 \pm 10 \%$ for 120 s sputtered electrode where:

$$
\mathrm{q}_{\text {irr. }}=\left[\left(\mathrm{q}_{1 \text { st charge }}-\mathrm{q}_{1 \text { st discharge }}\right) / \mathrm{q}_{1 \text { st charge }}\right] \times 100 \%
$$

The induced structural disorder did not affect the bulk of the graphite, but altered significantly its surface reactivity and almost doubled the amount of irreversible charge consumed in the formation of the SEI. These results imply that similar processes can be expected to occur during prolonged cycling of graphite anodes, which gradually develop a similar degree of surface disorder.

Impedance spectra (Figure 5) of un-altered and $120 \mathrm{~s}$ sputtered Mag-10 anodes at $0.05 \mathrm{~V}$ after three formation cycles show very similar impedance behaviour. The impedance spectra consist of a high frequency quasi-semicircle and low frequency tail. The semicircle is generally credited to the charge transfer resistance and double layer capacity at the electrode/electrolyte interface. However, the observed deviations from the semi-circle symmetry indicate complex character of the interface and multiple contributions to the 
impedance. ${ }^{23} \mathrm{~A}$ slight increase in the diameter of the semi-circle and pronounced contribution to the impedance close to the mid-frequency intercept may indicate slightly higher resistance of the SEI film for the sputtered electrode due to either a thicker or less ionically conductive SEI film. No change in the double layer charging contribution is seen and is therefore a further indication that sputtering alters the catalytic properties of the graphite surface, rather than the surface area.

The composition of the SEI layer on the Mag-10 anodes was studied ex situ with FTIR microscopy in the reflectance mode (Figure 6). A number of corresponding bands can be seen for both (a) un-altered and (b) 120s sputtered samples, nevertheless the band intensities for the sputtered anode are somewhat more intense, suggesting a thicker SEI film.

A qualitative analysis of the FTIR spectra indicates the presence of $\mathrm{PF}_{6}^{-}$and its decomposition products $\mathrm{Li}_{\mathrm{x}} \mathrm{PF}_{\mathrm{y}}$ and $\mathrm{Li}_{\mathrm{x}} \mathrm{PO}_{\mathrm{y}} \mathrm{F}_{\mathrm{z}}$ in the $\mathrm{SEI}$ on both anodes. Bands associated with $v_{\text {P-F }}$ are located at 827,901 and $971 \mathrm{~cm}^{-1}$, whereas the $v_{\text {P-O }}$ vibration is noted at $1020 \mathrm{~cm}^{-1} \cdot{ }^{24,25,26}$ The presence of organic compounds is documented by absorption bands at $2965 \mathrm{~cm}^{-1}\left(v_{\mathrm{C}-\mathrm{H}}\right), 1810-1730 \mathrm{~cm}^{-1}\left(v_{\mathrm{C}=\mathrm{O}}\right), 1480$ and $1405 \mathrm{~cm}^{-1}\left(\delta_{\mathrm{C}-\mathrm{H}}\right)$, $1186 \mathrm{~cm}^{-1}\left(v_{\mathrm{C}-\mathrm{O}-\mathrm{C}}\right)$ and $1077 \mathrm{~cm}^{-1}\left(v_{\mathrm{C}-\mathrm{O}}\right)$. The existence of residual EC is revealed by bands at $1807\left(v_{\mathrm{C}=\mathrm{O}}\right)$ and $1480 \mathrm{~cm}^{-1}\left(\delta_{\mathrm{C}-\mathrm{H}}\right)$. The group of bands at 1766,1743 and 1730 $\mathrm{cm}^{-1}\left(v_{\mathrm{C}=0}\right)$ are characteristic to alkyl carbonates $\mathrm{RCO}_{2} \mathrm{Li}$ and residual EC. Furthermore, the $v_{\mathrm{C}-\mathrm{H}}$ vibration at $2965 \mathrm{~cm}^{-1}$ corresponds to some other organic species apart from EC. However, the absence of any discernable bands at ca. $1650 \mathrm{~cm}^{-1}$ associated with $v_{\mathrm{C}=\mathrm{O}}$, 
indicates that lithium ethylene dicarbonate (LEDC), which is believed to be the main reduction product of $\mathrm{EC}$, is not present. ${ }^{27,28,29}$ The intense band at $1186 \mathrm{~cm}^{-1}$ consists of $v_{\mathrm{C}-\mathrm{O}-\mathrm{C}}$ vibrations from $\mathrm{RCO}_{2} \mathrm{Li}$ and $v_{\mathrm{C}-\mathrm{F}}$ vibrations from the $\mathrm{PVdF}$ binder. ${ }^{30}$ The $v_{\mathrm{C}-\mathrm{O}}$ band at $1077 \mathrm{~cm}^{-1}$ can be assigned to lithium methoxide $\left(\mathrm{LiOCH}_{3}\right)$ but the absence of distinguishable $v_{\mathrm{C}-\mathrm{H}}$ bands at 2793, 2850 and $2929 \mathrm{~cm}^{-1}$ suggests the presence of other species. ${ }^{27,31}$ This band can be tentatively allocated to $v_{\mathrm{C}-\mathrm{O}}$ vibrations from carbonate ethers and polyethylene oxide (PEO) type materials. Additionally, the absence of bands associated with $\mathrm{Li}_{2} \mathrm{CO}_{3}$ concurs with recent infrared results on graphitic anodes. ${ }^{32,33}$

Figure 7 shows the results of gas chromatography analysis of the SEI layer for both the un-altered and 120s sputtered Mag-10 anodes after three formation cycles. The GC traces were obtained after rinsing each electrode with $1.0 \mathrm{~mL}$ of dichloromethane (subsequent treatment with water followed by extraction into dichloromethane did not produce any additional peaks in the GC). Two peaks marked in the GC traces correspond to the dichloromethane solvent used in the GC experiment. A large peak at early retention time for the un-altered electrode corresponds to methanol contaminant.

Both GC traces show large peaks corresponding to residual DMC and EC from the electrolyte. Interestingly, there is a significant increase in the number of GC peaks for the 120 s sputtered electrode as compared to the un-altered electrode. The greater amount of decomposition products in the SEI for the modified electrode is consistent with the higher intensity of absorption bands observed in the FTIR spectra. Subsequent analysis of these peaks by GC-mass spectrometry afforded fragmentation patterns that are consistent 
with the formation of carbonate ethers and PEO type materials, which are compatible with the bands observed in the FTIR spectra. GPC analysis of the solutions obtained after immersion of each electrode in $0.5 \mathrm{~mL}$ DMF indicates the presence of materials with $\mathrm{M}_{\mathrm{w}}$ on the order of $1600 \mathrm{~g} \mathrm{~mol}^{-1}$ for the modified electrode, with no evidence of such species for the unmodified electrode.

The observation of fragments of ethylene oxides, carbonate ethers as well as their numerous short and long chain combinations, denotes products of ester exchange reactions, ${ }^{26,34,35,36,37}$ and ring-opening polymerisation of EC. ${ }^{26,38,39}$ The latter is catalysed by acids or bases and is thermodynamically driven by the extrusion of $\mathrm{CO}_{2}$ from the resulting polycarbonates. In this case, the reaction is base-catalysed by initial base formation at the freshly exposed electrode surfaces. The sputtered material surface contains more active sites which are likely to generate a higher concentration of base that catalyse the polymerisation and $\mathrm{CO}_{2}$ extrusion, and promote formation of more carbonate ethers and PEO-type polymers with higher molecular weights.

\section{Discussion}

We postulate that the gradual disordering of the graphite anode during prolonged cycling leads to a continuous solid electrolyte interphase (SEI) layer reformation. Fragmentation of surface graphene planes exposes fresh carbon edge sites to the electrolyte, which react immediately to continuously reform the SEI. The charge consumed in this long-term irreversible process diminishes the amount of cycleable lithium in the cell and shifts the cathode to a higher state of charge, reducing the overall reversible capacity of the cell. 
The mechanism of graphite disordering remains poorly understood, with only a couple of relevant studies present in the literature. ${ }^{3,4}$ Modelling studies ${ }^{40}$ of spherical graphitic carbon demonstrated that charge/discharge rates above $4 C$ can produce a stress in $5 \mu \mathrm{m}$

particle big enough to surpass the tensile strength for some types of graphitic carbons. ${ }^{41}$ It was also shown in this study that tensile strength is exceeded at rates above $16 C$ for all types of graphitic carbons. Interestingly, SEM images of cycled Mag-10 anodes do not show any evidence of structural breakdown or particle fracture when compared to fresh un-altered electrodes. ${ }^{18}$ However, taking into account the increased $I_{\mathrm{D}} / I_{\mathrm{G}}$ ratios observed in the Raman spectra of graphitic anodes from tested Li-ion cells we conclude that the crystalline disorder in graphite anodes is limited to the surface of the particle and does not affect the bulk of the material. ${ }^{3,4}$ We believe that the local structural damage at the surface of the graphitic electrodes occurs because of non-uniform current density distribution within the graphite electrode. Differences in ionic and electronic resistance within the electrode and the SEI layer contribute to this effect. This causes some particles on the surface of the anode to operate at a higher charge/discharge rate, which may produce large Li concentration gradients within the crystalline structure of graphite, and eventually surpass tensile strength of graphene planes.

\section{Conclusions}

The effect of the surface structural damage on graphitic anodes commonly observed in tested Li-ion cells was examined. Comparable surface structural disorder in graphite was artificially induced by means of argon-ion sputtering in Mag-10 synthetic graphite 
anodes. Raman microscopy, scanning electron microscopy (SEM) and Brunauer Emmett Teller (BET) measurements verified that Ar-ion sputtered Mag-10 electrodes exhibit a similar degree of surface degradation as the anodes from tested Li-ion cells. These artificially modified Mag-10 anodes showed twice the amount of irreversible charge capacity during the first formation cycle, compared to fresh un-altered anodes. Impedance spectroscopy and Fourier transform infrared (FTIR) spectroscopy signify the formation of a thicker and slightly more resistive SEI layer in the case of surface modified graphite anodes. GC-MS and GPC analysis indicated the presence of compounds with $\mathrm{M}_{\mathrm{w}}$ around $1600 \mathrm{~g} \mathrm{~mol}^{-1}$ formed on the surface of modified electrodes. No evidence of elevated $M_{w}$ species was seen for the unmodified electrode.

This study suggests that the structural degradation of the graphite in composite anodes during long-term cycling induces slow and continuous changes in the SEI layer. The observed reformation of the SEI is responsible in the cell impedance increase and the loss of Li-ion cell reversible capacity due to the shift of lithium inventory in cycled Li-ion cells. We believe that this effect constitutes an important mode of degradation of Li-ion cells and affects significantly their cycle life.

\section{Acknowledgements}

This work was supported by the Assistant Secretary for Energy Efficiency and Renewable Energy, Office of Vehicle Technologies of the U.S. Department of Energy under Contract No. DE-AC02-05CH11231. We wish to thank Dr. V. Battagalia and Dr. 
G. Liu for the provision of the electrode material and Dr. N. K. Beck for preparing the graphite pellets. 


\section{References}

1. J. Vetter, P. Novák, M. R. Wagner, C. Veit, K.-C. Möller, J. O. Besenhard, M. Winter, M. Wohlfahrt-Mehrens, C. Vogler, A. Hammouche, J. Power Sources, 147, 269 (2005).

2. From United States Advanced Batteries Consortium (USABC).

3. R. Kostecki, F. McLarnon, J. Power Sources, 119, 550 (2003).

4. E. Markevich, G. Salitra, M. D. Levi, D. Aurbach, J. Power Sources, 146, 146 (2005).

5. L. J. Hardwick, H. Buqa, M. Holzapfel, W. Scheifele, F. Krumeich, P. Novák, Electrochim. Acta, 52, 4884 (2007).

6. M. S. Dresselhaus, G. Dresselhaus, Adv. Phys., 511 (2002).

7. S. A. Solin, Adv. Chem. Phys, 49, 455 (1982).

8. T. Enoki, M. Suzuki, M. Endo, Graphite Intercalation Compounds and Applications, Oxford University Press, New York (2003).

9. R. Yazami, Y. F. Reynier, Electrochim. Acta, 47, 1217 (2002).

10. L. J. Hardwick, H. Buqa, P. Novák, Solid State Ionics, 177, 2801 (2006).

11. X. G. Han, S. M. Miao, X. P. Zhu, M. K. Lei, Appl. Surface Sci. 252, 5425 (2007).

12. R. Fong, U. von Sacken, J. R. Dahn, J. Electrochem. Soc., 137, 2009 (1990).

13. F. Tuinstra, J. L. Koenig, J. Chem. Phys., 53, 1126 (1970).

14. A. C. Ferrari, J. Robertson, Phys. Rev. B, 6114095 (2000).

15. G. Katagiri, H. Ishuda, A. Ishitani, Carbon, 26, 565 (1988).

16. R. Saito, A. Jorio, A.G. Souza Filho, G. Dresselhaus, M.S. Dresselhaus, M.A. Pimenta, Phys. Rev. Lett., 88, 02740 (2002). 
17. M. A. Pimenta, G. Dresselhaus, M. S. Dresselhaus, L. G. Cancado, A. Jorio and R. Saito Phys. Chem. Chem. Phys., 9, 1276 (2007).

18. U.S. Department of Energy Office of FreedomCAR and Vehicle Technologies, FY 2006 Progress Report for Energy Storage Research and Development, http://www1.eere.energy.gov/vehiclesandfuels/pdfs/program/2006 energy storage.

$\underline{\mathrm{pdf}}$

19. E. Peled, J. Electrochem. Soc., 147, 1658 (1979).

20. M. Winter, J. O. Besenhard, M. E. Spahr, P. Novák, Adv. Mater., 10, 725 (1998).

21. J. O. Besenhard, M. Winter, J. Yang, W. Biberacher, J. Power Sources, 54, 228 (1995).

22. M. Winter, P. Novák, A. Monnier, J. Electrochem. Soc., 145, 428 (1998).

23. D. P. Abraham, J. L. Knuth, D. W. Dees, I. Bloom, J. P. Christopherson, J. Power Sources, 170, 465 (2007).

24. M. Kerlau, M. Marcinek, V. Srinivasan, R. Kostecki, Electrochim. Acta., 52, 5422 (2007).

25. S. Laruelle, S. Pilard, P. Grugeon, J.-M. Tarascon, J. Electrochem. Soc., 151, A1204 (2004).

26. S. E. Sloop, J. B. Kerr, K. Kinoshita, J. Power Sources, 119, 330 (2003).

27. D. Aurbach, B. Markovsky, A. Shechter, Y. Ein-Eli, H. Cohen, J. Electrochem. Soc., 143, 3809 (1996).

28. G. V. Zhuang, K. Xu, H. Yang, T. R. Jow, P. N. Ross, J. Phys. Chem. B, 109, 17567 (2005). 
29. K. Xu, G. V. Zhuang, J. L. Allen, U. Lee, S. S. Zhang, P. N. Ross, T. R. Jow, J. Phys. Chem. B, 110, 7708 (2006).

30. D. Aurbach, B. Markovsky, A. Rodkin, M. Cojocaru, E. Levi, Hyeong-Jin Kim, Electrochim. Acta, 00, 1 (2002).

31. G. V. Zhuang, H. Yang, B. Blizanac, P. N. Ross, Electrochem Solid-State Lett., 8, A441 (2005).

32. K. Edström, M. Herstedt, D. P. Abraham, J. Power Sources, 153, 380 (2006)

33. S-H. Kang, D. P. Abraham, A. Xiao, B. L. Lucht, J. Power Sources, 175, 526 (2008)

34. H. Yoshida, T. Fukunaga, T. Hazama, M. Terasaki, M. Mizutani, M. Yamachi, J. Power Sources, 68, 311 (1997)

35. G. E. Blomgren, J. Power Sources, 81-82, 112 (1999)

36. D. Aurbach, Y. Ein-Ely, O.Y. Chusid, J. Electrochem. Soc., 141, 603 (1994)

37. D. Aurbach, B. Markovsky, I. Weissman, E. Levi, Y. Ein-Ely, Electrochim. Acta 45, 67 (1999)

38. L. Vogdanis, W. Heitz, Macromol. Chem., Rapid Commun. 7, 543 (1986)

39. L. Vogdanis, B. Martens, H. Uchtmann, F. Hensel, W. Heitz, Makromol. Chem. Macromol. Chem. Phys. 191, 5021 (1981)

40. J. Christensen, J. Newman, J. Solid State Electrochem., 10, 293 (2006)

41. M. Inagaki, New carbons: control of structure and functions. p 526, Elsevier, New York (2000) 


\section{Figure Captions}

Figure 1: $\quad$ SEM images of Mag-10 graphite electrodes: (a) un-altered, (b) 120s sputtered.

Figure 2: (a) Average Raman spectra of un-altered and sputtered (10s, 20s, 30s and 120s) Mag-10 anodes. Intensity is normalised to the G-band at $1580 \mathrm{~cm}^{-1}$ (b) $I_{\mathrm{D}} / I_{\mathrm{G}}$ ratio change with respect to sputtering time.

Figure 3: $\quad$ Raman image of the $\mathrm{I}_{\mathrm{D}} / \mathrm{I}_{\mathrm{G}}$ ratio from $48 \times 74 \mu \mathrm{m}$ area of un-altered (a) and 120s sputtered (b) Mag-10 graphite electrodes. The image was produced from deconvoluted Raman spectra collected at ca. $0.7 \mu \mathrm{m}$ resolution.

Figure 4: $\quad$ First galvanostatic $C / 25$ charge-discharge curves of un-altered $(-)$ and 120s sputtered (----) Mag-10 graphite in 1.0 M LiPF, EC:DMC 1:1 w/w.

Figure 5: Impedance spectra of un-altered (-) and 120s sputtered (…...) Mag-10 anodes after three formation $(C / 25)$ cycles in 1.0 $\mathrm{M} \mathrm{LiPF}_{6}, \mathrm{EC}: \mathrm{DMC} 1: 1$ w/w. The spectra were recorded at $0.05 \mathrm{~V}$ vs. $\mathrm{Li} / \mathrm{Li}^{+}, \mathrm{f}<10 \mathrm{mHz}, 50 \mathrm{kHz}>$.

Figure 6: $\quad$ Ex situ FTIR microscopy spectra of un-altered (a) and 120s sputtered (b) Mag-10 electrodes after three formation $(C / 25)$ cycles in $1.0 \mathrm{M} \mathrm{LiPF}_{6}$, EC:DMC 1:1 w/w. The electrodes were washed in DMC prior to the measurements.

Figure 7: GC traces of un-altered (a) and 120s sputtered (b) Mag-10 electrodes rinsed in dichloromethane. (Signals relating to dichloromethane are marked with asterix) 
Table 1: $\quad$ BET surface area $\left(\mathrm{m}^{2} \mathrm{~g}^{-1}\right)$ of un-altered and $120 \mathrm{~s}$ and 1800 s sputtered electrodes

\begin{tabular}{|c|c|}
\hline Sputter Time/ $\mathbf{s}$ & BET Surface Area/ $\mathbf{~ m}^{\mathbf{2}} \mathbf{g}^{\mathbf{- 1}}$ \\
\hline 0 & $10.0 \pm 0.4$ \\
\hline 120 & $9.6 \pm 0.4$ \\
\hline 1800 & $9.7 \pm 0.4$ \\
\hline
\end{tabular}




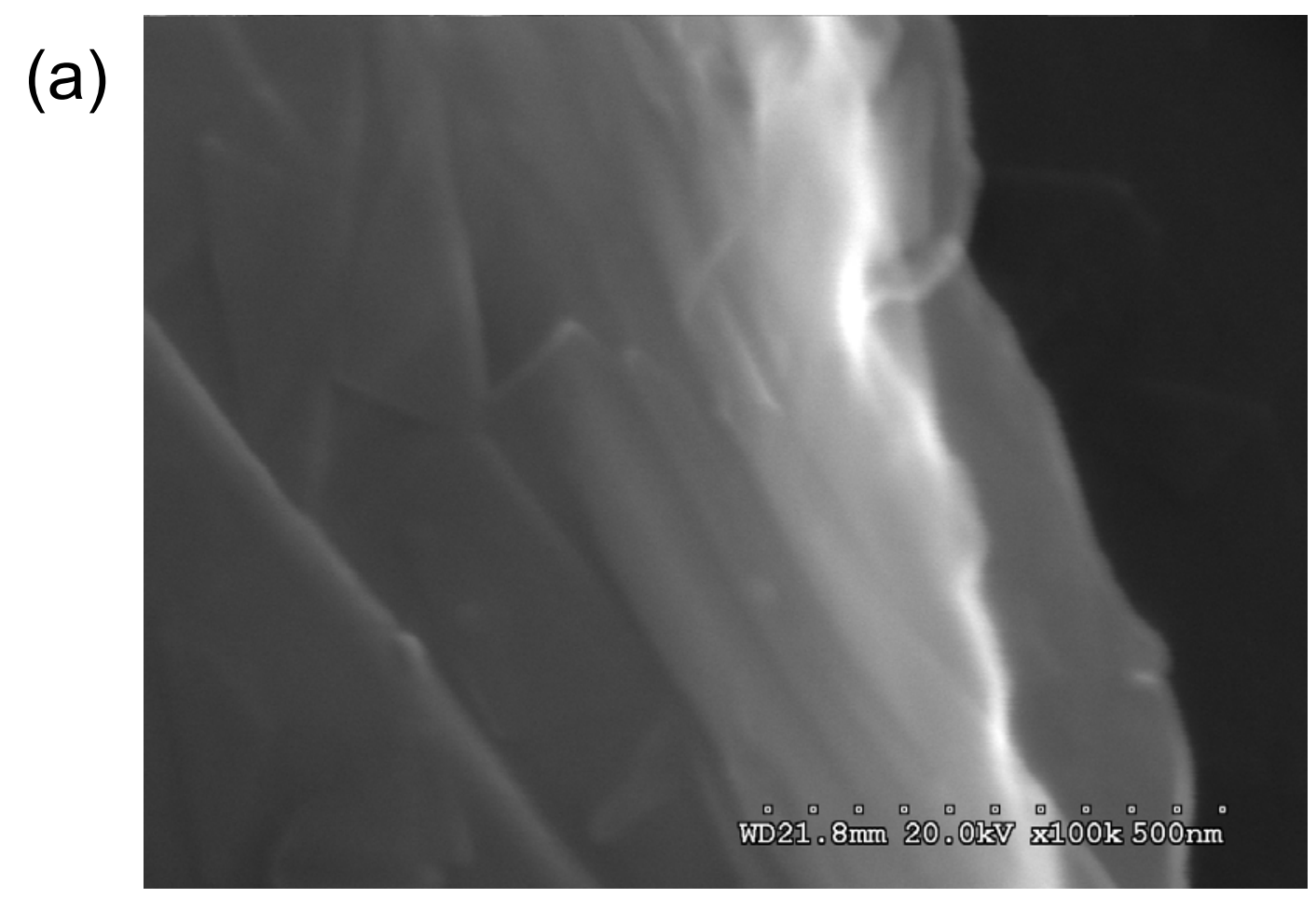

(b)

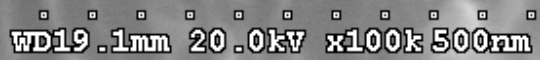

Fig 1. Hardwick et al. 

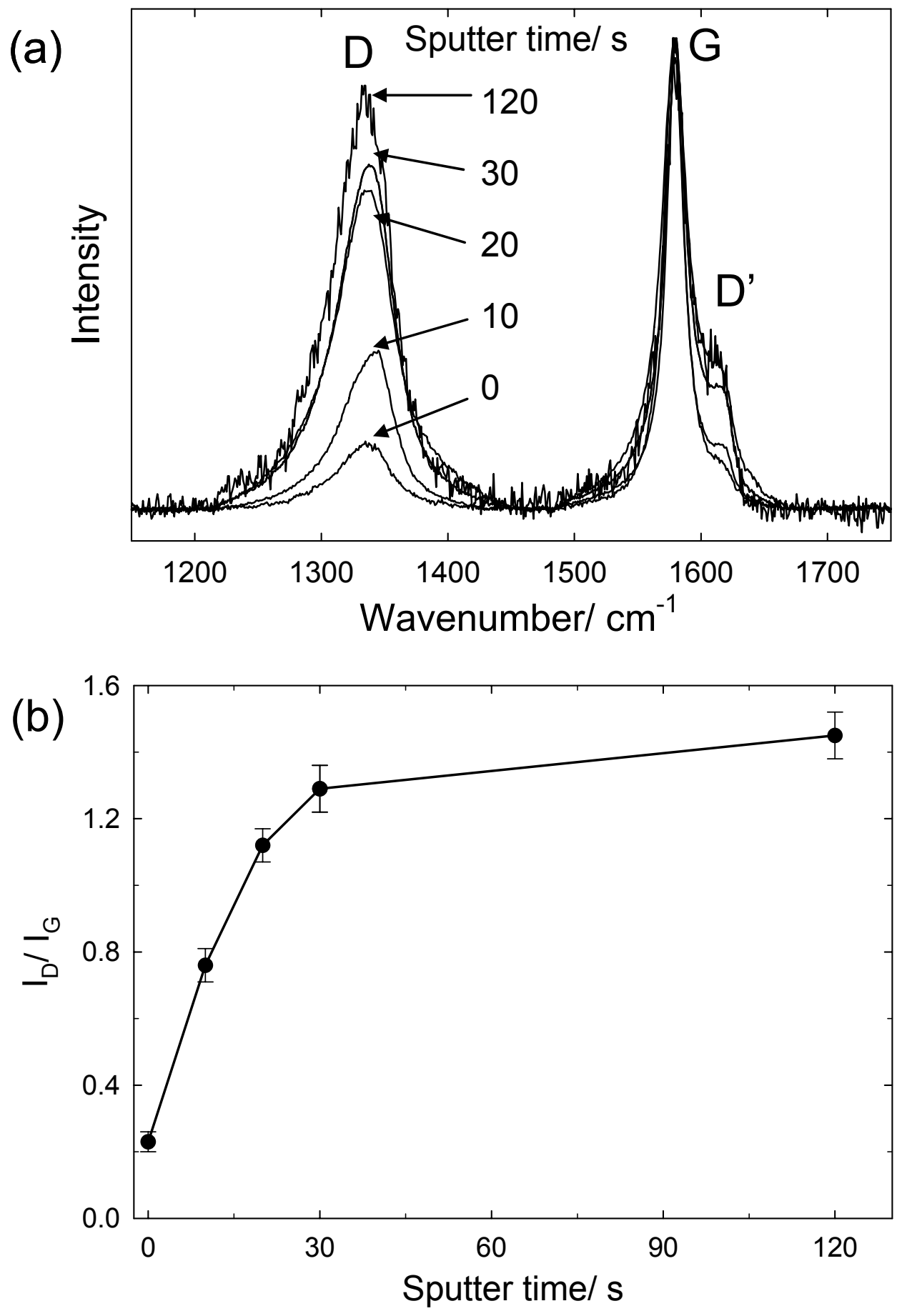

Fig 2. Hardwick et al. 


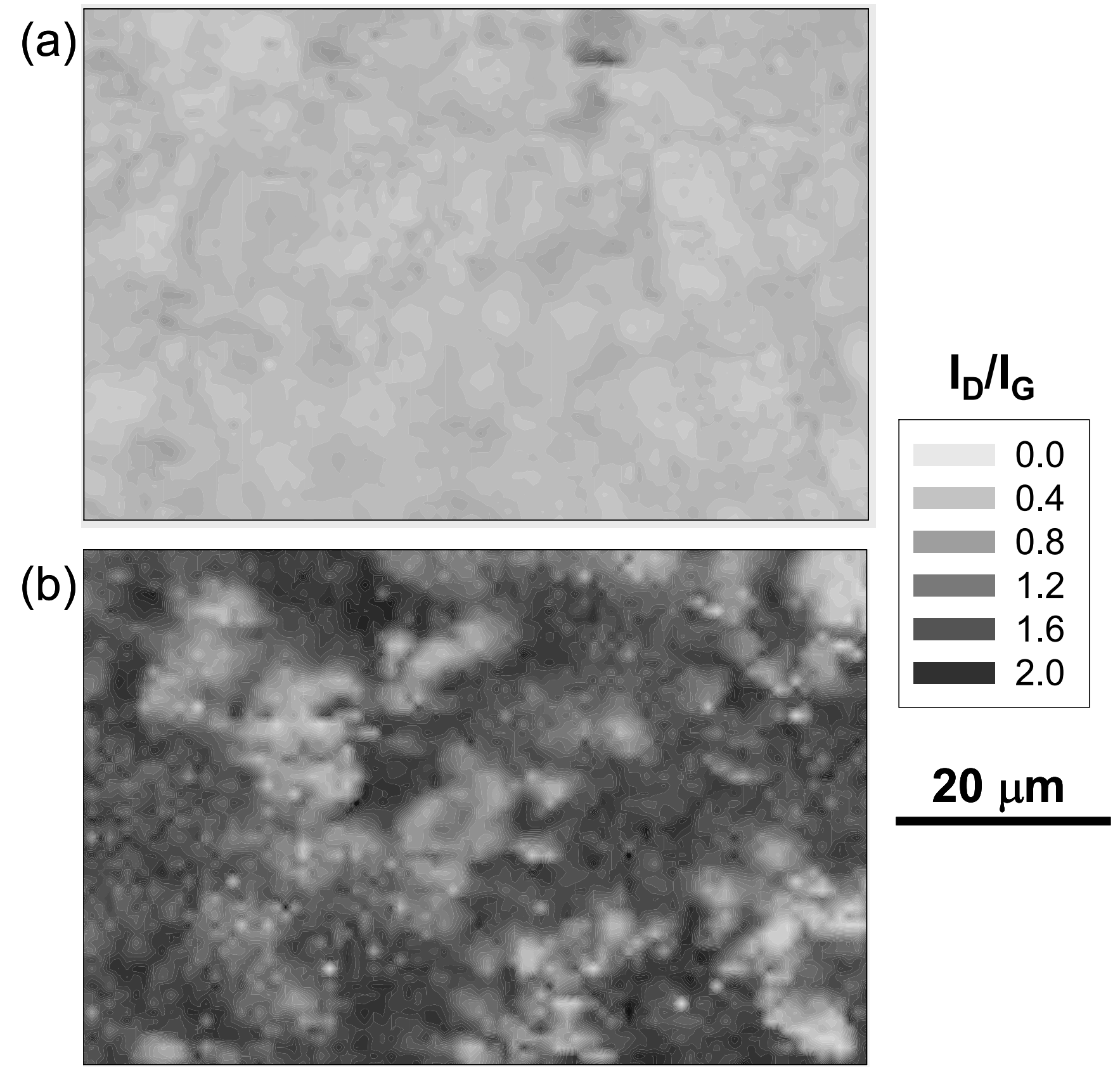

Fig 3. Hardwick et al. 


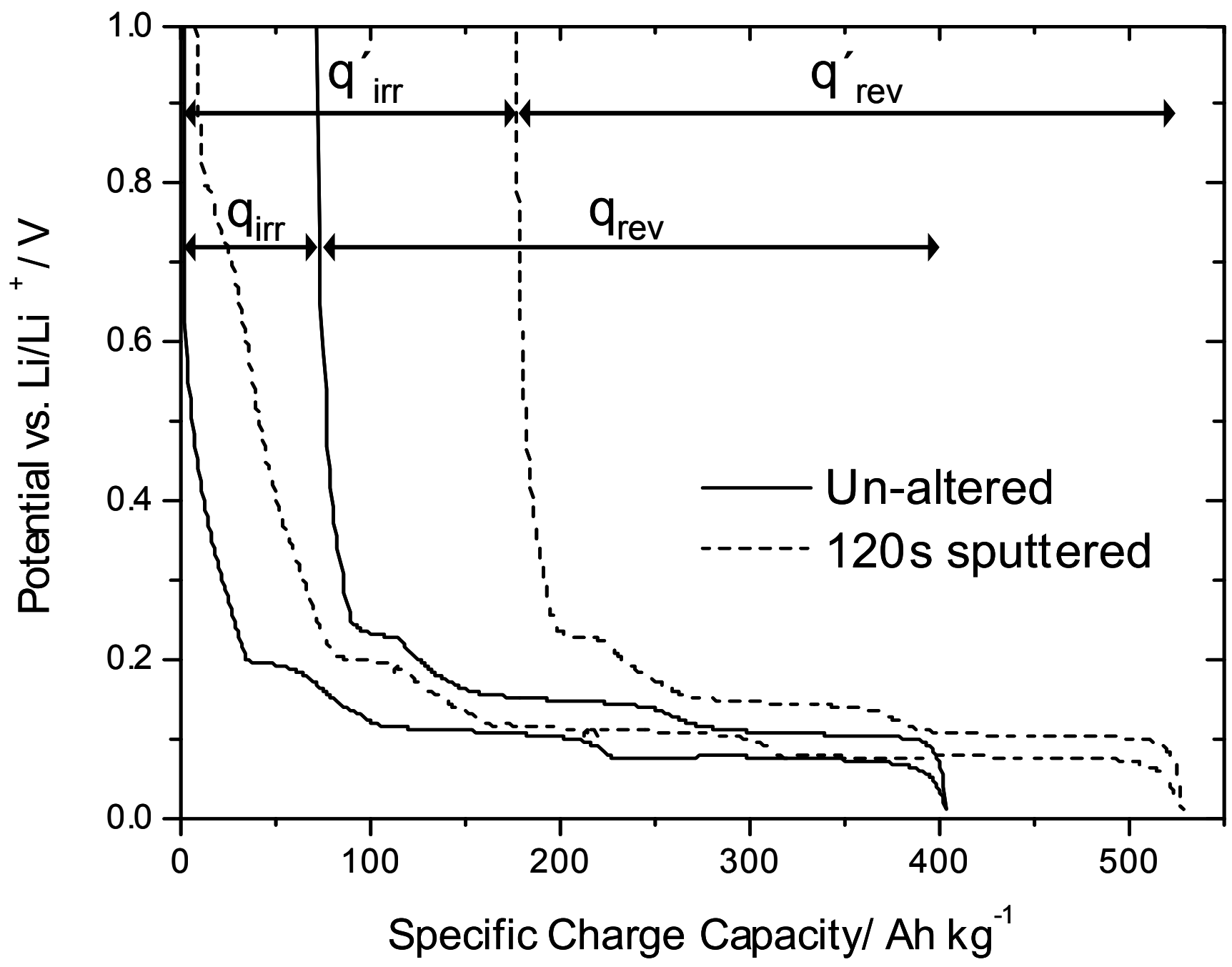

Fig 4. Hardwick et al. 


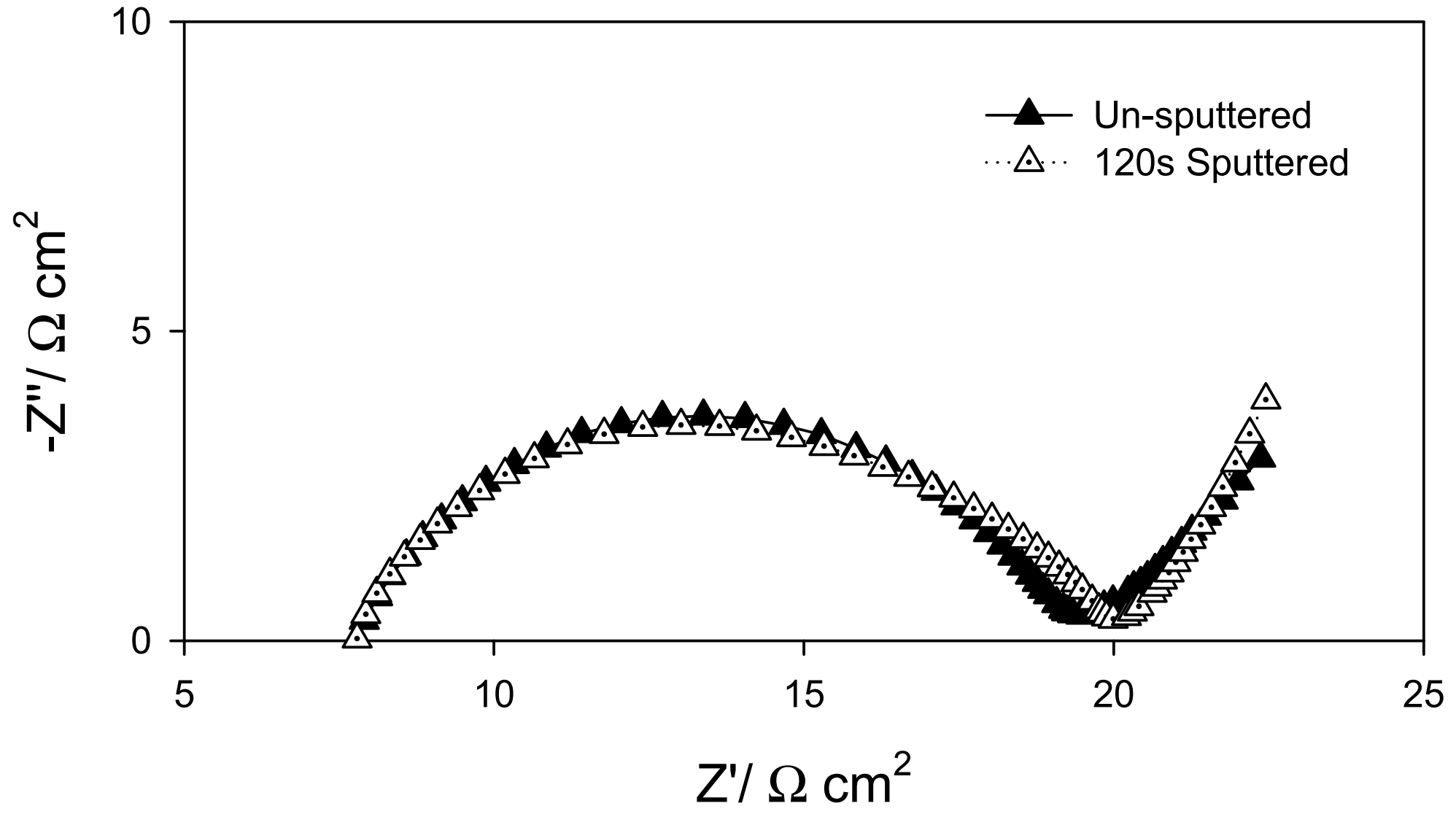

Fig 5. Hardwick et al. 


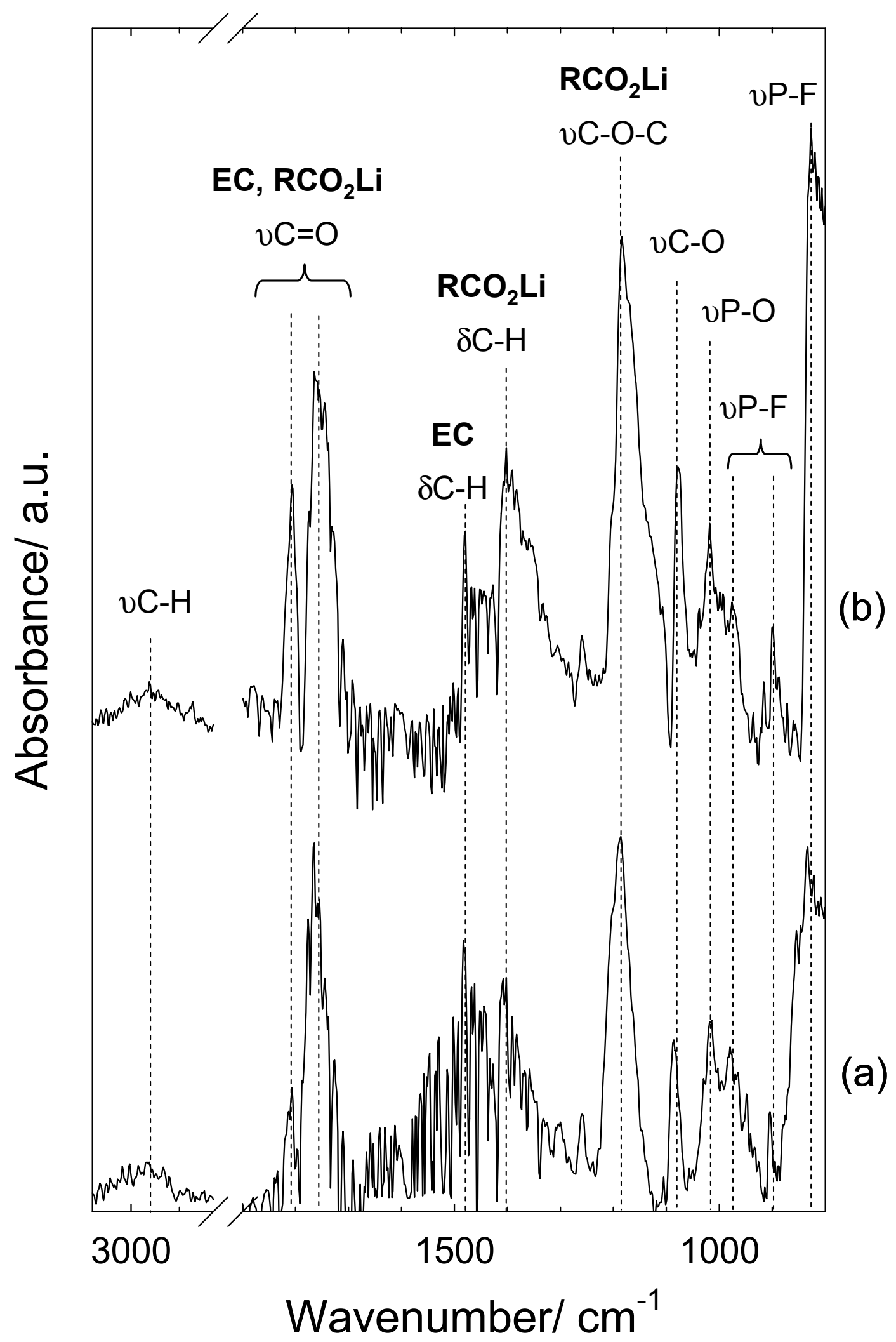

Fig 6. Hardwick et al. 


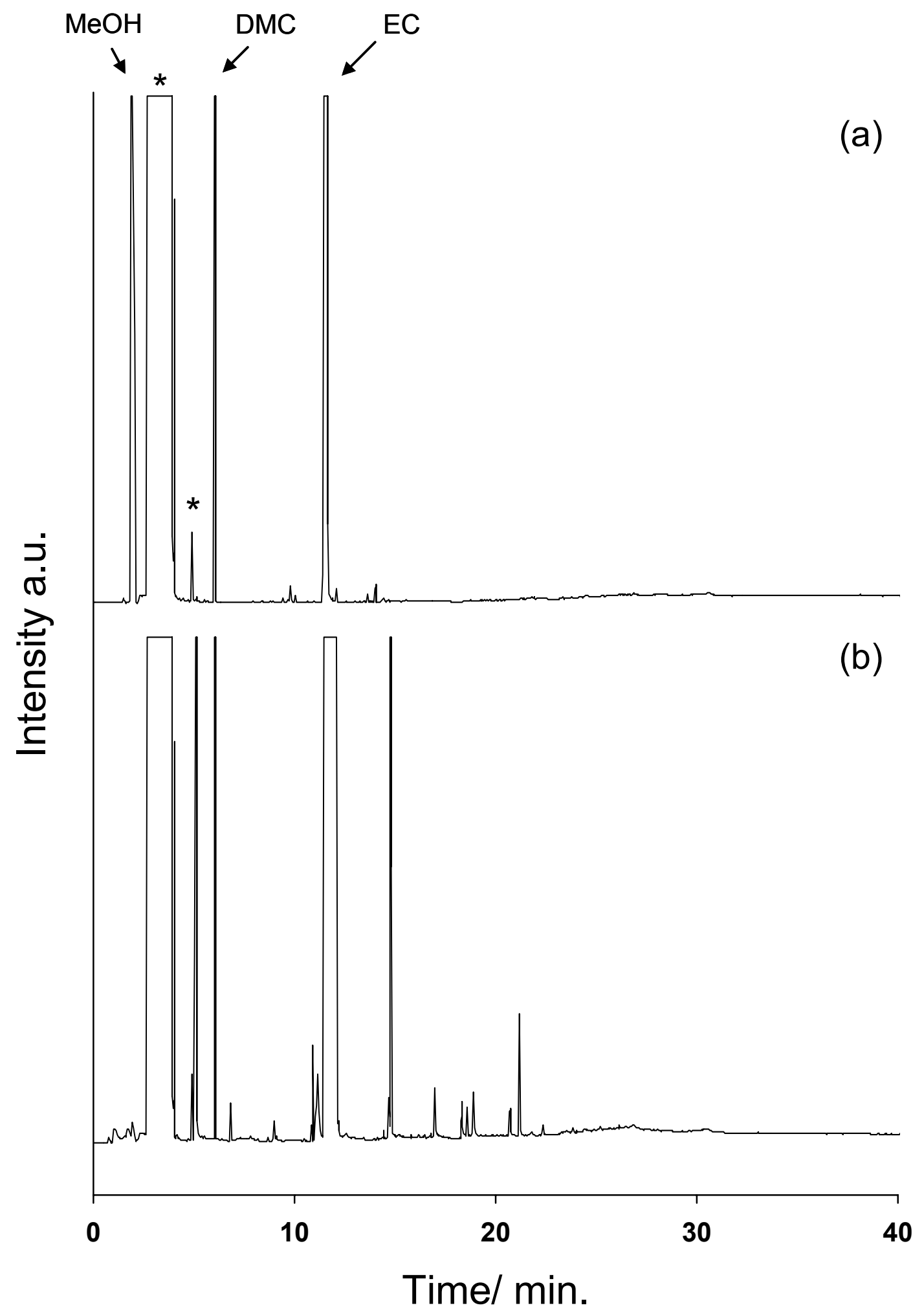

Fig 7. Hardwick et al. 